\title{
El reinado de Dios como asunto de la teología cristiana
}

\author{
Francisco de Aquino Júnior \\ Faculdade Católica (Fortaleza, FCF) \\ y Universidade Católica (Pernambuco) \\ Presbítero de la diócesis de Limoeiro do Norte (CE)
}

El reinado de Dios puede ser estudiado desde diferentes puntos de vista. Puede ser abordado desde el punto de vista bíblico, buscando identificar las raíces de esa expresión y su contenido, a través de diferentes usos y sentidos en la Sagrada Escritura (político, profético, apocalíptico, sapiencial, litúrgico, evangélico, paulino, etc.). Puede ser abordado desde el punto de vista dogmático, explicitando su importancia y centralidad en la cristología, en el discurso cristiano sobre Dios, en la eclesiología, en los sacramentos, en la antropología teológica, en la moral, en la pastoral, etc. Puede ser abordado desde el punto de vista histórico-pastoral, sea analizando las diferentes comprensiones e identificaciones de su realización a lo largo de los siglos; sea discerniendo las señales de su presencia en nuestra realidad actual; sea, todavía, confrontándose críticamente con sus posibles ideologizaciones en el pasado y en el presente. Todo esto es legítimo, importante y necesario para el desarrollo de una teología auténticamente cristiana. Sin embargo, nuestro abordaje del reinado de Dios, apoyándose de alguna forma en esos diferentes abordajes, se sitúa en otra perspectiva, no contraria, pero distinta de todas ellas.

El reinado de Dios será estudiado en una perspectiva sistemática-epistemológica como el asunto ${ }^{1}$ de la teología cristiana, aquello de lo que trata o de lo que

1. La expresión asunto está tomada no en sentido convencional idealista (de idea, tema, concepto), en contraposición u oposición a un sentido realista (de real, realidad), tal como hace Clodovis Boff, siguiendo la concepción althusseriana de "práctica teórica" (cfr. C. Boff, Teoria e prática: Teologia do político e suas mediações, pp. 144-150 (Petrópolis: Vozes, 1993); y Teoria do método teológico, pp. 56-58 
se ocupa la teología cristiana, en cuanto actividad estrictamente intelectiva, o sea, como "ámbito de realidad"2 a ser inteligido por la teología cristiana. Nuestro objetivo es mostrar cómo el reinado de Dios se presenta como la realidad y el concepto más amplio, fecundo y adecuado para explicitar el asunto de la teología cristiana, tanto en la pluralidad de sus elementos, aspectos o dimensiones, cuanto en su unidad estructural. De ahí el carácter sistemático y epistemológico de nuestro abordaje. Sistemático, en la medida en que se trata de una totalidad constituida por una pluralidad de notas, dimensiones, aspectos o elementos coherentemente articulados o estructurados ${ }^{3}$. Epistemológico, en la medida en que se trata de un aspecto fundamental y decisivo en el conocimiento teológico: la determinación de la realidad a ser conocida. A fin de cuentas, el modo de conocer una realidad cualquiera está determinado en gran parte por la constitución de esa realidad y por el modo como ella se deja aprehender intelectivamente.

Para eso nos confrontaremos con la problemática de la determinación del asunto o del "ámbito de realidad" de la teología cristiana y de su adecuada formulación, y explicitaremos el carácter sistemático y epistemológico de nuestra aproximación.

\section{La problemática del asunto de la teología cristiana}

Una de las cuestiones más decisivas y fundamentales en cualquier área de conocimiento es la determinación de la realidad a ser conocida. Y no solo por el hecho de que sin algún nivel de saber de esa realidad, no se puede avanzar en el

(Petrópolis: Vozes, 1998). Aquí, asunto está tomado en el sentido estrictamente etimológico de assumptus (asumido, tomado, ingerido, recibido), de assumere (tomar, recibir, ingerir, asumir, adoptar).

2. I. Ellacuría, "Hacia una fundamentación del método teológico latinoamericano", en Escritos teológicos I, pp. 187-218, en concreto, p. 212 (San Salvador: UCA Editores, 2000). "Por ámbito de realidad entendemos aquí no un objeto o una serie de objetos, sino la totalidad concreta e histórica con que se enfrenta una determinada actividad" (ibidem).

3. A propósito de los conceptos "sistema" y "estructura", cfr. X. Zubiri, Sobre la esencia, pp. 143-174 (Madrid: Alianza, 1985); y Estructura dinámica de la realidad, pp. 31-39 (Madrid: Alianza, 2006); I. Ellacuría, "La idea de estructura en la filosofía de Zubiri”, en Escritos filosóficos II, pp. 445-513 (San Salvador: UCA Editores, 1999). "En una estructura o en un sistema, cada una de las notas está por sí misma vinculada constitutivamente a las demás. Es decir, ninguna de las notas es ya real por sí misma, sino que solamente es real en unidad con el resto [...]. En un sistema, cada una de las notas ya no es nota sin más, sino que es 'nota de' todo el sistema. No se trata de que haya un sistema y que luego vengan las notas a formar parte en él, sino que son las notas mismas, en su vinculación estructural, las que constituyen el sistema"; A. González, Introducción a la práctica de la filosofía: Texto de iniciación, p. 154 (San Salvador: UCA Editores, 2005). 
conocimiento, sino, más radicalmente, porque el propio proceso de conocimiento está en gran parte condicionado por la realidad a ser conocida.

Es verdad que la determinación de la realidad a ser conocida es una actividad intelectual y en cuanto tal supone una concepción del proceso de conocimiento más o menos elaborada. Después de Kant no se puede hablar más de realidad "en sí", prescindiendo de las "condiciones de posibilidad" de su conocimiento. Pero también es verdad que el propio proceso de conocimiento está condicionado en buena medida por la realidad a ser conocida: el conocimiento de una realidad puramente biológica es distinto del conocimiento de una realidad personal; el conocimiento de una realidad puramente espiritual, si es que es posible, es diferente del conocimiento de una realidad histórica, por más espiritual que sea, y así sucesivamente. De modo que tampoco se puede hablar, críticamente, de las "condiciones de posibilidad" del conocimiento sin hablar de la realidad a ser conocida. Es tan ingenuo hablar de realidad "en sí", independientemente de su conocimiento (realismo ingenuo), como hablar de las "condiciones de posibilidad" del conocimiento, independientemente de la realidad a ser conocida (idealismo y subjetivismo ingenuos). Como bien afirma Xavier Zubiri, "el saber y la realidad son en su misma raíz estricta y rigurosamente congéneres. No hay prioridad de lo uno sobre lo otro" . Si, por un lado, "la investigación sobre la realidad necesita echar mano de alguna conceptuación de lo que sea el saber", por el otro lado, "una investigación acerca de las posibilidades de saber no puede llevarse a cabo [...] si no se apela a alguna conceptuación de la realidad" otras palabras, realidad y saber se implican y se condicionan mutuamente: la determinación de la realidad a ser conocida es una actividad intelectiva y el ejercicio de esa actividad intelectiva está determinado en buena medida por la configuración de la realidad que se busca conocer y, consiguientemente, por el modo como ella se deja aprehender.

Teniendo presente esa implicación entre saber y realidad, se puede, evidentemente, investigar de modo crítico tanto la realidad a ser conocida por una determinada ciencia (su asunto o "ámbito de realidad"), cuanto el proceso de conocimiento de esa realidad (actividad intelectiva). Aquí nos restringiremos a la problemática de la determinación de la realidad a ser inteligida por la teología cristiana.

Ahora bien, si la determinación del "ámbito de realidad" de las ciencias, como la sociología, economía, psicología, antropología, etc., es algo profundamente complejo, dada la diversidad de concepciones acerca de cada una de ellas y la dificultad de delimitar fronteras entre ellas, es mucho más compleja la determinación del "ámbito de realidad" de la teología cristiana.

4. X. Zubiri, Inteligencia sentiente: inteligencia y realidad, p. 10 (Madrid: Alianza, 2005).

5. Ibid., pp. 9 y s. 
Primero, por la ambigüedad y equivocidad de la expresión teo-logia. Y tanto en lo que dice respecto a la realidad en cuestión (théos), cuanto en lo que dice respecto a su proceso de intelección (logos). Pero aquí nos interesa apenas la primera cuestión: Dios como asunto de la teología cristiana. Y lo que sea esa realidad es de todo, menos evidente. Hay concepciones tan distintas acerca de $\operatorname{dios}^{6}$ que se puede dudar o cuestionar si con esa expresión se designa siempre la misma realidad, aunque con matices o acentos diversos. No por acaso ella encontró tanta resistencia en el ámbito cristiano y tardó tanto en convertirse en la definición convencional de la realidad a ser inteligida por la comunidad cristiana. Es que el contenido de esa expresión en el mundo antiguo estaba mucho más asociada a los filósofos griegos ${ }^{7}$ que a Jesús Cristo. No deja de ser significativo que aun en el siglo XIII, aquel que se ocupaba de la intelección de la revelación y de la fe cristiana fuese designado magister in Sacra Pagina y no teólogo, y que un Tomás de Aquino prefiriese la expresión Sacra Doctrina a la expresión teología $a^{8}$. No se trata, evidentemente, de contraponer sin más Atenas y Jerusalén, academia e Iglesia (Tertuliano), el Dios de Abraham, de Isaac y de Jacob y el Dios de los filósofos y de los sabios (Pascal), el Dios de los cristianos y el Dios de otras tradiciones religiosas. Se trata, simplemente, de determinar con mayor precisión a qué nos referimos cuando decimos Dios, por más loco y escandaloso que parezca ( $c f r .1$ Cor 1,23). Y para eso no basta el sentido etimológico de la expresión teo-logia. Es necesario determinar el contenido de la realidad denominada Théos o Dios.

Segundo, por el modo mismo de nuestro acceso a Dios. Por un lado, solo tenemos acceso a Dios en la medida en que Él se hace presente y actúa en nuestra vida y el mundo; no podemos hablar de "Dios en sî", independientemente de y del modo como Él se hace presente entre nosotros. Todo discurso sobre Dios está vinculado con algún acontecimiento o experiencia9 ${ }^{9}$. Por el otro lado, en ese hacerse presente y en ese actuar histórico de Dios, Él no se identifica sin más con alguna realidad o situación — no se agota en ninguna de ellas. De ahí

6. Cfr. Y. Congar, La foi et la théologie, pp. 125 y s. (Tournai: Desclée, 1962); J. B. Libanio y A. Murad, Introdução à teologia: perfil, enfoques, tarefas, pp. $62-76$ (São Paulo: Loyola, 1996); H. Rito, Introdução à teologia, pp. 25-36 (Petrópolis: Vozes, 1999); C. Boff, Teoria do método teológico, op. cit., pp. 548-560.

7. Cfr. W. Jaeger, La teología de los primeros filósofos griegos (México D. F.: FCE, 1998); G. Reale, História da Filosofia Antiga II, pp. 124-152, 335-373 (São Paulo: Loyola, 1994).

8. "Así, en la cuestión I de la Summa Theologica usa sólo tres veces el término 'teología' y 80 veces la expresión 'Doctrina Sagrada"'; C. Boff, Teoria do método teológico, op. cit., p. 555.

9. Es la mediación pragmática del lenguaje o su vinculación constitutiva con la praxis, cfr. L. Wittgenstein, Philosophische Untersuchungen, §§ 23, 30, 37, 43 (Frankfurt am Mein: Suhrkamp, 2003). 
el carácter paradójico de nuestro acceso a Dios: solo nos es accesible a través de acontecimientos históricos ${ }^{10}$, pero no se identifica con ni se agota en ninguno de esos acontecimientos. El propio Tomás de Aquino, hablando de Dios como asunto (subiectum) de la doctrina sagrada" ${ }^{11}$ o sea, "aquello de que se habla en esa ciencia", tiene que admitir que el conocimiento de Dios ("quien Él es") está mediado por los "efectos que Él produce en el orden de la naturaleza o de la gracia” (STh I, q.q, a.7). Y no por casualidad, se acostumbraba a definir la teología como intellectus fidei (inteligencia de la fe) y no como intellectus Dei (inteligencia de Dios). De modo que si no se puede identificar a Dios con ningún "efecto", acontecimiento o situación (trasciende a todo), tampoco se lo puede separar completamente de ellos, como si fuese posible hablar de Dios prescindiendo de esos "efectos", acontecimientos o situaciones (trasciende en y no de). La teología no trata, por lo tanto, de Dios "sin más", "en sî", independientemente de la historia humana. Eso sería imposible. Trata de Dios, sí, a partir de y en la medida en que Él se hace presente y actúa en la historia. Por esta razón, se debe determinar y formular de tal modo el asunto de la teología que Dios no sea identificado con, ni separado de, los acontecimientos históricos en los que se hace presente y actúa.

Tercero, por la necesidad y complejidad del acceso a Jesús de Nazaret. Conforme explicitamos antes, el acceso a Dios se da siempre y necesariamente

10. Inclusive lo que se podría llamar "revelación natural de Dios" tiene necesariamente un carácter histórico, en la medida en que "la captación nunca total de lo que es la naturaleza, implica un proceso, una diferenciación de puntos de vista, una mayor capacitación de las propias dotes humanas, una multiplicación y estructuración de posibilidades" intelectivas. Además, "puede haber ojos ciegos para determinadas dimensiones de la realidad, intereses obscuros que impiden la captación acertada y plena de esa realidad hasta el punto de que en principio no puede negarse que el hombre mismo y la humanidad vayan obturando posibilidades de intelección y de realización, con lo cual, dejados a su suerte, ni siquiera sean capaces de descubrir puntos fundamentales de la realidad y, sobre todo, lo que Dios manifiesta de sí en esa realidad. Diríamos entonces que la llamada revelación natural [...] tiene historia, es histórica"; I. Ellacuría, "Historia de la salvación", en Escritos teológicos I, op. cit. pp. 597-628, aquí p. 603.

11. "[L]a terminología de Tomás en ese punto puede causar extrañezas en el lector moderno. Nosotros diríamos que el 'sujeto' de la teología es el teólogo; su objeto, la revelación (o, quién sabe, hasta diríamos que el objeto es 'Dios'). Tomás, profundamente imbuido de la transcendencia de Dios, jamás podría decir eso. Se trata, pues, del problema de cómo traducir subjectum a los idiomas modernos. Tal vez un puente pueda ser el francés, que conoce, proveniente del latín subjectum, la palabra sujet, con el significado de 'asunto', 'tema"'; F. Taborda, "A missão do teólogo: comunicar a sabedoria. Uma lição de Tomás de Aquino”, REB 69/276 (2009), 885-913, aquí 906. Cfr. también J. P. Torrell, Iniciação a Santo Tomás de Aquino: sua pessoa e obra, pp. 184 y s. (São Paulo: Loyola, 1999). 
en situaciones o acontecimientos históricos que determinan en alguna medida tanto la experiencia de Él como el discurso sobre Él. Siendo así, la determinación del asunto de la teología pasa por la determinación de los acontecimientos en que Dios se hace presente y actúa. Para los cristianos, el acontecimiento histórico por excelencia, en el cual Dios se hace presente y actúa, es la praxis de Jesús de Nazaret. La experiencia cristiana de Dios está de tal modo vinculada a ese acontecimiento que Dios será nombrado por la comunidad cristiana como el Padre de Jesús Cristo (Creo en Dios Padre...) y no simplemente como Dios. El problema reside en la posibilidad real y efectiva de acceso a la praxis de Jesús de Nazaret. Y, aquí, la dificultad es doble. Por un lado, tiene que ver con la comprensión actual de lo que sea "histórico": un acontecimiento es histórico, para nosotros, "si, por lo que sabemos, ocurrió realmente de la manera como nosotros lo describimos" ${ }^{2}$. Por el otro lado, tiene que ver con las fuentes de acceso a Jesús de las cuales disponemos: "el Nuevo Testamento no nos da la narración 'objetiva' del Jesús histórico, sino la vivencia del Jesús histórico en la fe de la comunidad primitiva"13. Al principio, parece que estamos en un callejón sin salida. Queremos llegar a Jesús de Nazaret, saber quién fue y lo que hizo realmente, pero para eso no disponemos de otro acceso que el testimonio de fe de la comunidad eclesial. Sin embargo, habría que preguntarse si la concepción moderna de lo que sea "histórico" es tan objetiva como pretende ${ }^{14}$ y si el testimonio de fe de la comunidad eclesial es tan indigno de credibilidad o tan

12. R. Zuurmond, Procurais o Jesus histórico?, p. 41 (São Paulo: Loyola, 1999).

13. I. Ellacuría, "La Iglesia, signo de contradicción", en Escritos teológicos II, pp. 397-416, aquí p. 398 (San Salvador: UCA Editores, 2000). La expresión "Jesús histórico" no está tomada aquí en el sentido de Jesús (re)construido por las ciencias históricas (historicher Jesus), en oposición al Cristo testimoniado por las Escrituras (geschichtlicher biblischer Christus), para usar la formulación clásica de Martin Kähler, sino en el sentido amplio y fundamental del Jesús real, de Jesús de Nazaret, a quien las Escrituras confiesan como Cristo y a quien las ciencias históricas investigan, dentro de los límites de sus posibilidades.

14. Habría que comenzar diciendo con Zuurmond que la concepción moderna de historia es algo muy reciente y muy distinto de la mentalidad antigua. "Los historiadores antiguos [...] no escribían por 'interés histórico' [...]. Escribían principalmente con objetivos estéticos y didácticos y no tenían escrúpulos en guiarse por "preconceptos ideológicos"”. Además, "el mundo antiguo no hacía ninguna distinción fundamental entre lo que llamamos 'historia' y lo que llamamos 'leyenda' o 'saga' (y hasta cierto punto inclusive 'mito')". Sin hablar de que "la cosmovisión más común en el mundo helenista era la platónica", donde "realidad" tiene que ver mucho más con el mundo de las ideas que con el mundo empírico, y que los narradores antiguos "se sentían mucho menos bajo el control de la cronología como acontece entre nosotros"; R. Zuurmond, Procurais o Jesus histórico?, op. cit., pp. 44 y s. Pero todo eso sirve, a lo máximo, como advertencia para no buscar en la historiografía antigua lo que ella no ofrece. El problema es que posiblemente la historiografía moderna tampoco 
incapaz de ofrecer algún acceso a la vida real de Jesús de Nazaret. Importa, en todo caso, aquí, insistir en la necesidad de acceso a la praxis de Jesús de Nazaret para determinar con precisión el asunto de la teología cristiana, en la complejidad de tal acceso.

Cuarto, por el carácter complejo y conflictivo de la determinación de los signos actuales de la presencia y actuación de Dios - "signos de los tiempos" (GS 11). Ciertamente, para los cristianos, el acceso fundamental a Dios se da en la praxis de Jesús de Nazaret. Pero eso no es todo. A fin de cuentas, ni el Dios de Jesús está ausente de nuestro mundo ni, consiguientemente, la teología cristiana puede ser reducida a una especie de arqueología teologal. Teniendo como criterio último y fundamental la praxis de Jesús de Nazaret, es necesario discernir en qué situaciones o acontecimientos Él continúa haciéndose presente y actuando en la historia. Y eso, además de muy complejo, es profundamente conflictivo. Complejo, por el carácter paradojal del acceso a Dios, al cual nos referimos anteriormente (solo nos es accesible a través de acontecimientos históricos, pero no se identifica con ninguno de esos acontecimientos), y por la ambigüedad de los acontecimientos, en los cuales tenemos acceso a Él (lo manifiesta en ciertos aspectos y lo oculta y niega en otros aspectos ${ }^{15}$. Conflictivo, por las consecuencias prácticas de ese discernimiento, en el contexto mayor del conflicto de intereses presente en la sociedad y en la propia comunidad eclesial. Afirmar que Dios se hace presente o no en ciertos acontecimientos o que determinadas situaciones lo manifiestan o lo niegan, más o menos, no es algo social y eclesialmente indiferente. Tiene implicaciones prácticas, afecta motivaciones y conductas, en la medida en que (des)legitima eclesialmente intereses y comportamientos y en que orienta o guía la acción de los cristianos y de sus comunidades. Pero no obstante la complejidad y la conflictividad de ese discernimiento, es necesario hacerlo, tanto por fidelidad al "ámbito de realidad" de la teología cristiana, cuanto por honestidad para con la realidad histórica.

Todo eso muestra la complejidad de la problemática de la determinación del asunto de la teología cristiana: algo aparentemente tan simple y evidente - ¿de qué trata la teología cristiana? - se revela, en verdad, profundamente problemático y complejo. Pero, al mismo tiempo, indica o delimita las fronteras de su "ámbito de realidad": no trata de Dios sin más, sino de la presencia y la actuación

ofrece la objetividad absoluta que parece pretender. Ella depende o está condicionada "por lo que sabemos" y eso relativiza enormemente tal objetividad.

15. Es que "la presencia y acción del Espíritu están ordinariamente mezcladas con las limitaciones, errores y pecados humanos. Si fue difícil para muchos discernir en el carpintero de Nazaret al Hijo, al Mesías, al Cristo, de modo que muchos lo rechazaron, es mucho más difícil discernir la presencia del Espíritu en medio de personas y acontecimientos muchas veces confusos y ambiguos"; V. Codina, "Não extingais o Espírito” (1 Ts 5,19): iniciação à pneumatologia, p. 70 (São Paulo: Paulinas, 2010). 
de Dios en la historia (pasado, presente y futuro), según la praxis de Jesús de Nazaret. Importa, ahora, formular de modo lo más adecuado posible el asunto o el "ámbito de realidad" de la teología cristiana.

\section{Formulación adecuada del asunto de la teología cristiana}

Después de abordar la problemática de la determinación del asunto de la teología cristiana, ahora nos confrontaremos con la problemática de su adecuada formulación. Por formulación adecuada entendemos una que da cuenta, conceptualmente, de la complejidad del "ámbito de realidad" de la teología cristiana, tal como lo explicamos en el apartado anterior. Se trata, por lo tanto, de encontrar y crear un concepto o una formulación que exprese del modo más objetivo y global posible el asunto o "ámbito de realidad" de la teología cristiana.

Ya vimos que ella no trata de Dios en sí, independientemente de la historia de la humanidad, ni siquiera de una experiencia cualquiera de Dios. Trata de Dios en cuanto y en la medida en que se hace presente y actúa en la historia, tal como se dio en la praxis de Jesús de Nazaret, a quien la comunidad cristiana confiesa como el Cristo. Por lo tanto, para determinar con precisión el "ámbito de realidad" de la teología cristiana, tenemos que aproximarnos a la praxis de Jesús de Nazaret. Ella es el lugar por excelencia del acceso a Dios y el criterio fundamental de discernimiento de su presencia y actuación en la historia. Consiguientemente, es el lugar y el criterio más adecuado para la determinación y la formulación del asunto de la teología cristiana.

En lo que se dice respecto a la praxis de Jesús de Nazaret, los estudios bíblicos ${ }^{16}$ y cristológicos $^{17}$ de las últimas décadas han mostrado de modo cada

16. Cfr. G. Bornkamm, Jesus de Nazaré, pp. 60-90 (Petrópolis: Vozes, 1976); R. Schnackenburg, Reino y reinado de Dios. Estudio bíblico-teológico (Madrid: Faz, 1974); y "Reino de Deus", en J. B. Bauer, Dicionário de teologia bíblica II, pp. 947-964 (São Paulo: Loyola, 1988); J. Jeremias, Teologia do Novo Testamento, pp. 159-193 (São Paulo: Paulus-Teológica, 2004); W. G. Kümmel, Síntese teológica do Novo Testamento, pp. 21-108 (São Leopoldo: Sinodal, 1983); R. Fabris, Jesus de Nazaré: história e interpretação, pp. 89-179 (São Paulo: Loyola, 1988); J. Mateos, A utopia de Jesus (São Paulo: Paulus, 1994); J. Gnilka, Jesus de Nazaré: mensagem e história, pp. 83-153 (Petrópolis: Vozes, 2000); G. Vanoni y B. Heininger, Das Reich Gottes (Würzburg: Echter, 2002); X. Léon-Dufour, Agir segundo o Evangelho. Palavra de Deus, pp. 23-54 (Petrópolis: Vozes, 2003); C. Petersen, Die Botschaft Jesu vom Reich Gottes. Aufruf zum Neubeginn (Stuttgart: Kreuz, 2005); B. J. Malina, O evangelho social de Jesus: o reino de Deus em perspectiva mediterrânea (São Paulo: Paulus, 2004).

17. Cfr. W. Pannenberg, Theologie und Reich Gottes (Gütersloh: Gerd Mohn, 1971); L. Boff, Jesus Cristo Libertador, pp. 38-59 (Petrópolis: Vozes, 1991); E. Schillebeeckx, Jesus: história de um vivente, pp. 99-263 (São Paulo: Paulus, 2008); J. I. González Faus, Acesso a Jesus: ensaio de teologia narrativa, pp. 34-46 
vez más consensuado que ella tiene que ver fundamentalmente con el reinado de Dios (basiléia tou Theou). Ciertamente, hay divergencias en lo que dice respecto al contenido y al significado del reinado de Dios, mas no en lo que dice respecto a su centralidad en la vida de Jesús de Nazaret. "Es incontestable que el punto central del anuncio de Jesús fue la soberanía de Dios o el reinado de Dios [...] la soberanía de Dios puede ser literalmente considerada el centro de su actividad. Pues es el punto central en torno del cual todo lo demás se organiza, no sólo el mensaje sino también su actividad de curar enfermos y de realizar milagros, y su imperativo ético"18. En palabras de Rinaldo Fabris, "el núcleo en torno del cual gravita el anuncio y la actividad histórica de Jesús consiste en el Reino de Dios"19. Para Kümmel, el anuncio de la proximidad del reinado de Dios consistió en el "resumen de toda la predicación de Jesús" y la expresión reinado de Dios era "el término que mejor servía para caracterizar toda la predicación de Jesús" 20 . Podemos decir, por lo tanto, que el reinado de Dios es la realidad y el concepto

(São Paulo, Loyola, 1981); W. Kasper, Der Gott Jesu Christi, pp. 205-216 (Mainz: Grünwald, 1982); K. Rahner, Curso Fundamental da Fé, pp. 297-302 (São Paulo: Paulus, 1989); H. Kessler, "Cristología", en T. Schneider, Manual de dogmática I, pp. 219-400, aquí 242-247 (Petrópolis: Vozes, 2002); J. L. Segundo, A história perdida e recuperada de Jesus de Nazaré, pp. 142-262 (São Paulo: Paulus, 1997); J. Sobrino, Jesus, o Libertador: a história de Jesus de Nazaré, pp. 103-201 (Petrópolis: Vozes, 1996); J. Moltmann, O Caminho de Jesus Cristo, pp. 137-164 (Petrópolis: Vozes, 1994); y Quem é Jesus Cristo para nós hoje?, pp. 11-32 (Petrópolis: Vozes, 1997); B. Ferraro, Cristologia, pp. 77-96 (Petrópolis: Vozes, 2004); J. Ratzinger, Jesus de Nazaré, pp. 57-70 (São Paulo: Planeta, 2007).

18. J. Gnilka, Jesus de Nazaré, op. cit., p. 83; G. Bornkamm, Jesus de Nazaré, op. cit., p. 60; R. Schnackenburg, Reino y reinado de Dios, op. cit., p. 67; J. Jeremias, Teologia do Novo Testamento, op. cit., p. 160; J. Sobrino, Jesus, o Libertador, op. cit., pp. 105-108; X. Léon-Dufour, Agir segundo o Evangelho, op. cit., p. 24; W. Pannenberg, Theologie und Reich Gottes, op. cit., p. 9; W. Kasper, Der Gott Jesu Christi, op. cit., p. 210; H. Kessler, "Cristología", op. cit., p. 242; J. Ratzinger, Jesus de Nazaré, op. cit., p. 58.

19. R. Fabris, Jesus de Nazaré, op. cit., p. 104.

20. W. G. Kümmel, Síntese teológica do Novo Testamento, op. cit., p. 34. Pero mientras Kümmel, refiriéndose concretamente a Mc 1,14ss, afirma que ese resumen y esa expresión "es de autoría del propio evangelista y no puede ser entendida [El pasaje bíblico] como siendo un dicho transmitido del propio Jesús" (ibidem), González Faus, tratando de los posibles accesos a la vida de Jesús, afirma taxativamente: "Existen dos palabras, solamente dos, que nadie duda de que Jesús las pronunció; y no las pronunció una vez apenas; al contrario, eran frecuentes y constantes en su vida. Simplemente dos palabras-llaves: el término Abbá y la fórmula reino de Dios. Y ambos términos son ciertamente el mejor y el más expresivo resumen de la vida de Jesús y de su sentido"; J. I. González Faus, Acesso a Jesus, op. cit., p. 35. 
más central y más fundamental en la vida de Jesús. De tal manera que "quien se entrega a Jesús, se entrega al reinado de Dios. Eso es inevitable, pues 'la causa de Jesús' fue y es el 'reino de Dios"'21.

Ahora bien, si nuestro acceso a Dios es un acceso histórico (a), si el acontecimiento histórico por excelencia, en el cual tenemos acceso a Dios es la praxis de Jesús de Nazaret (b), y si esa praxis tiene que ver fundamentalmente con la realización del reinado de Dios (c), en el reinado de Dios debe consistir, entonces, el asunto de la teología cristiana - aquello de lo que se ocupa o de que trata la teología cristiana. En este sentido, para que seamos rigurosos y consecuentes, en vez de teo-logia, aquí deberíamos hablar de basiléia-tou-teo-logia: intelección (logia) del reinado de Dios (basiléia tou Theou). La razón de esto, como bien formuló Ignacio Ellacuría, es un principio teológico-epistemológico fundamental: "lo mismo que Jesús vino a anunciar y realizar, esto es, el reino de Dios, es lo que debe constituirse en el objeto unificador de toda la teología cristiana" ${ }^{2}$. En una formulación más precisa y rigurosa:

Todo hacer eclesial debe realizarse en pro-seguimiento del Jesús histórico. Aplicado el principio a nuestro caso, debe decirse: si el objeto fundamental de la misión de Jesús fue el reino de Dios, debe serlo también de la praxis eclesial y del momento ideológico de esa praxis eclesial. Aunque se necesite determinar ulteriormente cómo entendió Jesús el reino de Dios y cómo debe entenderse en cada situación histórica el reino de Dios predicado por Jesús — dos tareas estrictamente teológicas_, se afirma de manera resuelta como interpretación adecuada de la vida y la misión de Jesús que su objeto fundamental es el reino de Dios y que dentro del marco del reino de Dios y en su realización histórica es como deben surgir los demás temas teológicos, tanto en la línea de la interpretación teórica como en la línea de los proyectos y de las acciones. Se trata, evidentemente, de lo que debe hacer una teología cristiana y no cualquier teología. Y lo que ha de hacer una teología cristiana no se sabe entendiéndola como una de las realizaciones específicas de un presunto esquema genérico, sino tomando con absoluta seriedad la vida de Jesús, sea innovadora o no, surja o no de una experiencia irreductible. ${ }^{23}$

De modo que, aun cuando no se puedan excluir otras formulaciones, ni se les tome de antemano como inadecuadas, se puede, sin duda, afirmar que la

21. J. Moltmann, O Caminho de Jesus Cristo, op. cit., p. 11.

22. I. Ellacuría, "Aporte de la teología de la liberación a las religiones abrahámicas en la superación del individualismo y del positivismo", en Escritos teológicos II, op. cit. pp. 193-232, aquí pp. 202 y s.

23. I. Ellacuría, "La teología como momento ideológico de la praxis eclesial", en Escritos teológicos I, op. cit., pp. 163-185, aquí pp. 175 y s. 
expresión reinado de Dios es muy fecunda y apropiada para una formulación adecuada del asunto o del "ámbito de realidad" de la teología cristiana. Y eso por varias razones.

En primer lugar, habla de Dios a partir de su actuación histórica. Más que un espacio territorial (reino), basiléia tou Theou designa el actuar y la acción soberana de Dios en la historia, el ejercicio de su poder regio (reinado) ${ }^{24}$, y, en cuanto tal, "incluye formalmente a Dios" e "incluye formalmente su reinado en la historia", pero "los incluye en una unidad intrínseca". Por ser reinado de Dios, "apela a la totalidad del Dios revelado por Jesús y en Jesús; pero apela a esa totalidad según el modo propio de revelación de Jesús”. Y aquí se supera todo riesgo de inmanentismo e historicismo. Pero por ser reinado de Dios, "apela a la historia y al hombre como lugar de presencia y actuación del Dios de Jesús Cristo", sin que eso comprometa la "autonomía del inmanente", ni reduzca a Dios al "reinado histórico". Y con esto se supera todo riesgo de trascendentalismo y de espiritualismo ${ }^{25}$. La expresión reinado de Dios permite, por lo tanto, hablar de Dios a partir de su actuación histórica, y, así, tomar en la propia formulación del asunto o del "ámbito de realidad" de la teología cristiana la unidad radical entre la realidad a ser inteligida (Dios) y su acceso histórico (reinado) ${ }^{26}$.

En segundo lugar, asume de modo consecuente el carácter teologal fundamental de la praxis de Jesús de Nazaret. No solo habla de Dios a partir de un acontecimiento histórico, sino que lo hace a partir de aquel acontecimiento

24. Cfr. R. Schnackenburg, Reino y reinado de Dios, op. cit., pp. 323-325; J. Jeremias, Teologia do Novo Testamento, op. cit., p. 162; E. Schillebeeckx, Jesus: história de um vivente, op. cit., p. 135; R. Fabris, Jesus de Nazaré, op. cit., p. 106; W. Kasper, Der Gott Jesu Christi, op. cit., p. 210; J. Moltmann, O Caminho de Jesus Cristo, op. cit., pp. 11 y s.; J. Sobrino, Jesus, o Libertador, op. cit., p. 111; H. Kessler, "Cristología", op. cit., pp. 242 y s.; X. Léon-Dufour, Agir segundo o Evangelho, op. cit., pp. 26 y s.; J. Ratzinger, Jesus de Nazaré, op. cit., p. 64.

25. I. Ellacuría, "Aporte de la teología de la liberación a las religiones abrahámicas", op. cit., pp. 176 y s. Diferente de lo que parece ser tanto para R. Schnackenburg, Reino y reinado de Dios, op. cit., p. 83, como para O. Cullmann, Heil als Geschichte, pp. 58 y s., 235 (Tübingen, 1965). Contra Schnackenburg vale la crítica de Jeremias a la "interpretación espiritualista" de la presencia del reinado de Dios entre nosotros (Teologia do Novo Testamento, op. cit., p. 166). Contra Cullmann vale la crítica de González Faus a su concepción ilustrada de historia, $c f r$. "El problema de la historia en la teología de Gustavo Gutiérrez", Revista Latinoamericana de Teología 18, 1989, 335-364, aquí 342.

26. "Dios y el reino son absolutamente inseparables para nosotros; porque Dios es Abbá, llega su reino, y el Dios de Jesús no es accesible al margen del reino. El reino es la proximidad liberadora de Dios para los hombres" (J. I. González Faus, "El problema de la historia", op. cit., p. 40). 
histórico en el cual la comunidad cristiana reconoce de forma radical y definitiva la presencia y la actuación de Dios en la historia: la praxis de Jesús de Nazaret. Y aquí está lo más propio y lo más específico de la teología cristiana frente a otras teologías: tomar con absoluta seriedad la praxis de Jesús de Nazaret como lugar fundamental de la presencia y actuación de Dios y como criterio de discernimiento de su presencia y actuación históricas. Lo que sea la realidad de Dios, cuáles sean sus designios, cuál sea su modo de presencia y actuación en la historia, etc., no se sabe, cristianamente, sino a partir de Jesús de Nazaret. Cualquier adjetivo o nominación de Dios (omnipotente, omnipresente, omnisciente, absoluto, trascendente, infinito, ser, alteridad, etc.) tiene que pasar por el filtro de la vida y la praxis de Jesús de Nazaret. Ella es la "piedra angular" (base, fundamento) y la "piedra de toque" (medio de evaluar) de la teología cristiana. Y, aquí, de nuevo, la expresión reinado de Dios se muestra extremamente fecunda y adecuada, ya que permite hablar de Dios a partir del acontecimiento histórico fundamental en el cual Él se dio a conocer: la praxis de Jesús de Nazaret.

En tercer lugar, al aceptar como criterio la praxis de Jesús de Nazaret, se asume también de modo consecuente el carácter teologal de la praxis eclesial y de la praxis histórica total. El reinado de Dios que la teología cristiana busca inteligir no es otro que el que fue anunciado y realizado por Jesús de Nazaret, según las Escrituras, y que continúa siendo anunciado y realizado por sus seguidores e, inclusive, por personas y grupos que, a pesar de no conocerlo, ni de identificarse como sus seguidores, realizan, sin embargo, lo que Él anunció y realizó. Tiene que ver, por lo tanto, con la praxis de Jesús de Nazaret (acontecimiento histórico fundamental) y con el dinamismo histórico ("signos de los tiempos") desencadenado por ella ( 1 Cor 4,20; 1 Jn 2,6), acorde o identificado con ella (Lc 10,25-37; Mt 25,31-46). Es el problema de la relación reinado de Dios-Iglesiapueblo de Dios ${ }^{27}$. A la realidad y al concepto "reinado de Dios" corresponden la realidad y el concepto "pueblo de Dios", que aun cuando no se identifica sin más con la Iglesia, tampoco es completamente independiente de ella. La verdad es que no existe reinado de Dios sin pueblo de Dios, ni pueblo de Dios sin reinado de Dios. Dicho con otras palabras, Dios solo reina en la medida en que tiene un pueblo sobre el cual ejercer su gobierno y solo en la medida en que un pueblo concreto es de hecho gobernado por Dios, vive de acuerdo con sus designios. Ese pueblo se puede llamar pueblo de Dios.

En cuarto lugar, tiene un carácter englobante y totalizador. Es un hecho que la teología cristiana siempre trató de muchos temas, problemas, aspectos,

27. Cfr. R. Schnackenburg, Reino y reinado de Dios, op. cit., pp. 107-127; I. Ellacuría, "Iglesia como pueblo de Dios", en Escritos teológicos II, op. cit., pp. 317-342; J. Sobrino, Jesus, o Libertador, op. cit., pp. 107 y s.; J. Ratzinger, Jesus de Nazaré, op. cit., pp. 60 y ss.; A. González, Reinado de Dios e imperio: ensayo de teología social, pp. 139 y ss. (Santander: Sal Terrae, 2003). 
dimensiones, etc. Y siempre buscó tratarlos de modo más o menos coherente y sistemático, donde todo tiene que ver con todo. La gran pregunta es siempre cómo abordar esa pluralidad de temas, preguntas y dimensiones en su unidad estructural radical. De nuevo, la categoría reinado de Dios permite asumir y expresar de modo consecuente esa pluralidad en su unidad radical: habla de todo (Jesús, Dios, Iglesia, hombre-mujer, sacramentos, moral, economía, política, cultura, religión, etc.) a partir y en vista del señorío de Dios en este mundo, tal como se dio en la praxis de Jesús de Nazaret. Tomar el reinado de Dios como realidad y concepto englobante y totalizador de la teología cristiana hace que, por un lado, "no se deje fuera nada de lo que es el mensaje revelado", y, por el otro lado, "permite acercarse connaturalmente a las cosas de este mundo, porque, en definitiva, el reino de Dios, punto central del mensaje de Jesús, alude a la presencia reinante de Dios en este mundo" ${ }^{28}$. Aquí se manifiesta el carácter englobante y totalizador de la realidad y del concepto reinado de Dios. Tanto en lo que dice respecto a la pluralidad y a la unidad de sus notas, cuanto a lo que dice respecto a la "tensión escatológica" del "ya-pero todavía no" 29 que lo caracteriza.

Finalmente, ofrece un criterio objetivo de verificación de su realización histórica. La característica del reinado de Dios, dice Joachim Jeremias, es la realización del "ideal de justicia real, siempre ansiado, mas nunca cumplido en la tierra". Y la "justicia real" dice, fundamentalmente, respecto a la "protección con la que el rey cuida a los desamparados, frágiles y pobres, a las viudas y a los huérfanos". Según Jeremias, "con la constatación de que Jesús anunció la consumación del mundo como algo que estaba a punto de irrumpir, aun así no se explicitó totalmente su predicación sobre la basiléia; por el contrario, su trazo decisivo aún no ha sido descrito": la "oferta de salvación a los pobres".

28. I. Ellacuría, "Teología de la liberación frente al cambio socio-histórico en América Latina", en Escritos teológicos I, op. cit., pp. 313-345, aquí p. 315.

29. Es la tesis de Oscar Cullmann frente a la "escatología consecuente" (realidad futura) de A. Loisy y A. Schweitzer y contra la "escatología realizada" (realidad presente) de C. H. Dodd, cfr. O. Cullmann, Einführung in das Neue Testament, pp. 38 y s. (München-Hamburg: Siebstern Taschenbuch, 1968). A propósito de esa "tensión escatológica", aunque con formulaciones distintas y prescindiendo del concepto de historia subyacente; $c f r$. G. Bornkamm, Jesus de Nazaré, op. cit., pp. 62 y ss., 82 y ss.; R. Schnackenburg, Reino y reinado de Dios, op. cit., pp. 101 y ss.; J. Jeremias, Teologia do Novo Testamento, op. cit., pp. 163-175; W. G. Kümmel, Síntese teológica do Novo Testamento, op. cit., pp. 33-41; R. Fabris, Jesus de Nazaré, op. cit., pp. 106-112; J. Gnilka, Jesus de Nazaré, op. cit., pp. 132-146; X. Léon-Dufour, Agir segundo o Evangelho, op. cit., pp. 29 y s.; W. Pannenberg, Theologie und Reich Gottes, op. cit., pp. 9-29; E. Schillebeeckx, Jesus: história de um vivente, op. cit., pp. 142-148; H. Kessler, "Cristología", op. cit., p. 244; J. Sobrino, Jesus, o Libertador, op. cit., pp. 118 y s.; J. Moltmann, O Caminho de Jesus Cristo, op. cit., pp. 23 y s. 
Aquí, precisamente, dice él, está el "corazón de la predicación de Jesús", por más escandaloso que parezca ${ }^{30}$. Aquí encontramos un criterio objetivo de verificación histórica de la realización o no del reinado de Dios en nuestro mundo, así como de nuestra adhesión o rechazo a él: la existencia de pobres y oprimidos en nuestro mundo es, en sí misma, la expresión más clara y más radical de la negación de la justicia de Dios. Nuestra reacción a esa situación de injusticia y opresión determina nuestra adhesión o nuestro rechazo al reinado de Dios (Lc 10,25-37; Mt 25,31-46). En otras palabras, si el reinado de Dios tiene que ver, fundamentalmente, con la justicia a los pobres y oprimidos de este mundo, ellos se constituyen en criterio y medida fundamental de su realización histórica o no y de nuestra adhesión o rechazo a él.

Por todas estas razones, la expresión reinado de Dios parece extremamente fecunda y apropiada para una adecuada formulación del asunto o del "ámbito de realidad" de la teología cristiana. Dicho de la manera más simple y más objetiva posible, el reinado de Dios es el asunto de la teología cristiana: aquello de que se ocupa y de lo que trata la teología cristiana. Por eso mismo, como dijimos anteriormente, más que de teo-logia, deberíamos hablar de basiléia-tou-teologia: intelección (logia) del reinado de Dios (basiléia tou Theo). Pero, dada la extrañeza de esa expresión entre nosotros y el uso común y universal de la expresión teología, conservamos esta última, dándole, sin embargo, un contenido que extrapola su sentido etimológico. Seguiremos, por lo tanto, hablando de teología, pero entendiéndola como intelección del reinado de Dios.

\section{Aproximación sistemática-epistemológica}

Después de haber mostrado en qué sentido el reinado de Dios puede y debe ser tomado como la realidad y el concepto más adecuado y más fecundo para la determinación del asunto de la teología cristiana, nos resta explicitar el carácter y el potencial sistemático y epistemológico de nuestra aproximación al reinado de Dios.

\subsection{Carácter y potencial sistemáticos}

En el apartado anterior, al destacar el carácter englobante y totalizador del reinado de Dios, llamábamos la atención sobre la pluralidad de temas, problemas, aspectos y dimensiones de la teología cristiana, y de la necesidad de una

30. J. Jeremias, Teologia do Novo Testamento, op. cit., pp. 162, 176. Cfr. G. Bornkamm, Jesus de Nazaré, op. cit., pp. 69-75; R. Fabris, Jesus de Nazaré, op. cit., pp. 112-118; X. Léon-Dufour, Agir segundo o Evangelho, op. cit., pp. 95-102; G. Vanoni y B. Heininger, Das Reich Gottes, op. cit., pp. 91 y s.; E. Schillebeeckx, Jesus: história de um vivente, op. cit., pp. 165-172; J. Sobrino, Jesus, o Libertador, op. cit., pp. 123-135; J. Moltmann, O Caminho de Jesus Cristo, op. cit., pp.19-22; A. González, Reinado de Dios e imperio, op. cit., pp. 142-151. 
aproximación sistemática. Y afirmábamos que el reinado de Dios (como realidad y concepto) permite asumir y expresar de modo consecuente esa pluralidad en su unidad radical: trata de todo a partir de y en vista de la realización del reinado de Dios. Más que un tema entre otros, aun cuando sea el más importante, el reinado de Dios es tomado aquí como lo más propio y específico de la teología cristiana - todo es tratado a partir de y en vista de su realización histórica- y como su "ámbito de realidad" - todo encuentra en él su lugar y su importancia. De ahí su carácter y su potencial sistemáticos: capacidad de articular de modo coherente la teología cristiana en su totalidad. En el reinado de Dios, la teología cristiana encuentra, por lo tanto, su unidad radical: ya sea en lo que dice respecto a lo específicamente cristiano de la teología (punto de vista), ya sea en lo que dice respecto a la unidad estructural radical de la teología cristiana (ámbito de realidad).

La fecundidad de ese carácter y de ese potencial sistemático del reinado de Dios puede ser constatada, sobre todo, en el desarrollo de la teología de la liberación de las últimas décadas - a pesar de todos los límites que se puedan identificar en ella. Ignacio Ellacuría llega, incluso, a definirla como una teología del reinado de Dios ${ }^{31}$. Y Jon Sobrino, al tratar la "centralidad del reino de Dios en la teología de la liberación" y "el carácter totalizante del reino de Dios", se pregunta explícitamente "si y cómo el reino de Dios, como objeto teológico central, tiene la capacidad de organizar todos los contenidos de la teología". Después de indicar su fecundidad en el tratamiento de algunos de los temas principales de la teología, concluye afirmando que "el reino de Dios no es sólo objeto central de la teología, sino lo que puede organizar [...] la totalidad de la teología" o "la mejor manera de potencializar la totalidad de la teología" ${ }^{\prime 2}$.

Ciertamente, no es este el sitio apropiado para presentar la novedad y la fecundidad de la aproximación de los variados temas teológicos, en el horizonte y en la perspectiva del reinado de Dios, en la teología de la liberación. En todo caso, no resistimos la tentación de al menos indicar algunas aproximaciones,

31. Cfr. I. Ellacuría, "Fe y justicia”, en Escritos teológicos III, pp. 307-373, aquí p. 311 (San Salvador: UCA Editores, 2002); "La teología como momento ideológico de la praxis eclesial", op. cit., pp. 175 y s.; "Relación teoría y praxis en la teología de la liberación", op. cit., pp. 235, 240 y s.; "Teología de la liberación frente al cambio socio-histórico en América Latina", op. cit., pp. 313-345, aquí p. 315; "Aporte de la teología de la liberación a las religiones abrahámicas”, op. cit., pp. 193-232, aquí pp. 202 y s.

32. J. Sobrino, "Centralidad del reino de Dios en la teología de la liberación", en I. Ellacuría y J. Sobrino, Conceptos fundamentales de la teología de la liberación I, pp. 467-510, aquí pp. 505 y s., y 509 (Madrid: Trotta, 1994). 
cuyos desarrollos consideramos más relevantes y fecundos: la cristología ${ }^{33}$, la teología ${ }^{34}$, la eclesiología $a^{35}$, los sacramentos ${ }^{36}$, la espiritualidad ${ }^{37}$, el martirio ${ }^{38}$, la pastoral ${ }^{39}$, las cuestiones sociales, políticas, económicas, culturales y ambien-

33. Cfr. J. Sobrino, Jesus, o Libertador, op. cit.; y A fé em Jesus Cristo: ensaio a partir das vítimas (Petrópolis: Vozes, 2000).

34. Cfr. R. Muñoz, O Deus dos cristãos (Petrópolis: Vozes, 1986); y Trindade de Deus amor oferecido em Jesus, o Cristo (São Paulo: Paulinas, 2002).

35. Cfr. Ó. Romero, "A Igreja, corpo de Cristo na história: segunda carta pastoral do Arcebispo D. Romero (06/08/1977)", en J. Sobrino, I. Martín-Baró y R. Cardenal, Voz dos sem voz: a palavra profética de D. Óscar Romero, pp. 95-126 (São Paulo: Paulinas, 1987); I. Ellacuría, "Iglesia como pueblo de Dios", en Escritos teológicos II, op. cit., pp. 317-342; J. de Santana, El desafío de los pobres a la iglesia (San José: DEI, 1985); J. Sobrino, "La iglesia samaritana y el principio-misericordia", en El principiomisericordia: bajar de la cruz a los pueblos crucificados, pp. 31-45 (Santander: Sal Terrae, 1992); X. Alegre, "La iglesia que nace de la Pascua. Seguimiento de Jesús y opción por los pobres", Revista Latinoamericana de Teología 80, 201, 141-160.

36. Cfr. V. Codina, "Sacramentos", en I. Ellacuría y J. Sobrino, Conceptos fundamentales de la teología de la liberación II, pp. 267-294 (Madrid: Trotta, 1994); F. Taborda, Sacramentos, práxis e festa: para uma teologia latino-americana dos sacramentos (Petrópolis: Vozes, 1994).

37. Cfr. J. Sobrino, "Seguimento de Jesus", en C. F. Samanes y J. J. Tamayo-Acosta, Dicionário de Conceitos Fundamentais do Cristianismo, pp. 771-775 (São Paulo: Paulus, 1999); F. de Aquino Júnior, Viver segundo o espírito de Jesus Cristo. Espiritualidade como seguimento (São Paulo: Paulinas, 2014); J. M. Castillo et al., El seguimiento de Jesús (Madrid: Fundación Santa María, 2004).

38. Cfr. J. Sobrino, "De una teología solo de la liberación a una teología del martirio", en J. Comblin, J. I. González Faus y J. Sobrino, Cambio social y pensamiento cristiano en América Latina, pp. 101-121 (Madrid: Trotta, 1993); y Jesus, o Libertador, op. cit., pp. 366-390; J. M. Tojeira, El martirio ayer y hoy: testimonio radical de fe y justicia (San Salvador: UCA Editores, 2005); Revista Concilio 299, 2003/1; L. Weckel, Um des Lebens willen. Zu einer Theologie des Martyriums aus befreiungstheologischer Sicht (Mainz: Matthias-Grünwald, 1998).

39. Cfr. A. Brighenti, A pastoral dá o que pensar: a inteligência da prática transformadora da fé (São Paulo: Paulinas, 2006). 
tales $^{40}$, el (macro) ecumenismo ${ }^{41}$ y el método teológico ${ }^{42}$. Estos desarrollos no son todavía exhaustivos o conclusivos. Sin embargo, a pesar de sus limitaciones, se revelan como extremamente fecundos, tanto en los resultados ya alcanzados, cuanto en la dirección apuntada y en las posibilidades ofrecidas. De modo que, sea por lo que ya dio de sí en la teología de la liberación, sea por lo que aún puede dar de sí, abordar el reinado de Dios como asunto de la teología cristiana tiene un carácter y un potencial sistemático indiscutible: permite abordar variados temas, aspectos y dimensiones de la teología, tanto en su especificidad e irreductibilidad como en su unidad radical.

\subsection{Carácter y potencial epistemológico}

El abordaje del reinado de Dios como asunto de la teología cristiana también tiene un carácter y un potencial epistemológico, en la medida en que determina con precisión el asunto o "ámbito de realidad" de la teología cristiana y, así, determina, en buena forma, su acceso intelectivo. Después de todo, como afirmábamos al inicio de nuestra reflexión, el modo de conocer una realidad cualquiera está determinado, en gran parte, por la constitución de esa realidad y por su acceso intelectivo.

$\mathrm{Al}$ afirmar que (a) la teología cristiana trata del reinado de Dios, y no de Dios sin más; que (b) el reinado de Dios es una realidad práxica-histórica, por más espiritual y trascendente que sea; que (c) tiene en la praxis de Jesús de Nazaret su criterio fundamental y definitivo, aun cuando no se agote en ella; que (d) él tiene que ver con todos los aspectos y con todas las dimensiones de la vida humana,

40. Cfr. I. Ellacuría, "Utopía y profetismo desde América Latina: un ensayo de soteriología histórica", en Escritos teológicos II, op. cit., pp. 233-293; y "El reino de Dios y el paro en el Tercer Mundo", ibid., pp. 295-305; A. González, Reinado de Dios e imperio, op. cit.; F. de Aquino Júnior, Dimensão sócio-estrutural do reinado de Deus: escritos de teologia social (São Paulo: Paulinas, 2010).

41. J. de Santana, Ecumenismo e libertação: reflexões sobre a relação entre a unidade cristã e o Reino de Deus (São Paulo: Vozes, 1991); G. Tiel, Ecumenismo na perspectiva do reino de Deus: uma análise do movimento ecumênico de base (São Leopoldo: Sinodal, 1998); F. de Aquino Júnior, "Igreja dos pobres: sacramento do povo universal de Deus. Tópicos de uma eclesiología macroecumênica da libertação", en L. Tomita, M. Barros y J. M. Vigil, Pluralismo e Libertação: por uma teologia latino-americana pluralista a partir da fé cristã, pp. 193-214 (São Paulo: Loyola, 2005).

42. I. Ellacuría, "Hacia una fundamentación del método teológico latinoamericano", op. cit.; "La teología como momento ideológico de la praxis eclesial", op. cit.; y "Relación teoría y praxis en la teología de la liberación", op. cit.; J. Sobrino, "Teología en un mundo sufriente: la teología de la liberación como 'intellectus amoris", en El principio-misericordia, op. cit., pp. 47-80; F. de Aquino Júnior, A teologia como intelecção do reinado de Deus: o método da teologia da libertação segundo Ignacio Ellacuría (São Paulo: Loyola, 2010). 
no agotándose en ninguna de ellas; y que (e) tiene en los pobres y oprimidos de este mundo su lugar privilegiado de realización y su principio histórico de verificación y des-ideologización, por más universal que sea y más allá de las buenas intenciones, estamos ya determinando, en buena medida, cómo se da el proceso de conocimiento teológico.

Al contrario de lo que piensa Clodovis Boff, por ejemplo, el punto de partida de la teología cristiana no son las formulaciones dogmáticas o positivas de fe (fides quae) ${ }^{43}$, por más que el conocimiento teológico, como un modo más profundo y elaborado de saber, suponga algún nivel de saber o reflexión ${ }^{44}$. Primero, porque el asunto o el "ámbito de realidad" de la teología cristiana es el reinado de Dios y no un conjunto de afirmaciones o formulaciones dogmáticas ${ }^{45}$. Estas ya son elaboraciones teológicas que remiten siempre a aquello, y en lo cual encuentran o no razón. Segundo, porque en lo que dice respecto al proceso de conocimiento, no es nada evidente que "sólo la teoría genera teoría" cosas reales permanecen atrás del proceso cognitivo" 47 , que "la praxis no es mediación teórica alguna" ${ }^{" 48}$ y que saber y realidad constituyen esferas u órdenes esencialmente "heterogéneos, aunque combinables"49. Por un lado, la teoría es un momento de la acción humana: su momento consciente y reflexivo. Tiene que ver con el modo humano de enfrentarse con las cosas. Y el propio leguaje utilizado en las elaboraciones teóricas es, como bien entendió Wittgenstein, parte de una praxis concreta o de una forma concreta de vida ${ }^{50}$. Por el otro lado, si saber y realidad se constituyen esferas u órdenes completamente "heterogéneos", el saber jamás sería saber de la realidad, ni siquiera de la supuesta heterogeneidad entre saber y realidad. De modo que, sea por causa de su ámbito de realidad (reinado de Dios), sea debido al propio proceso de intelección (momento de la praxis), el punto de partida de la teología cristiana es la realización histórica del reinado de Dios, tal como se dio en la praxis de Jesús de Nazaret.

43. C. Boff, Teoria do método teológico, op. cit., p. 111; y "Retorno à arché da teologia", en L. C. Susin, Sarça ardente. Teologia na América Latina: prospectivas, pp. 145-187, 148 y s. (São Paulo: Paulinas, 2000).

44. C. Boff, Teoria do método teológico, op. cit.; y Teoria e prática, op. cit., p. 154.

45. Y aquí se insiere la crítica pertinente de Jon Sobrino a lo que él denomina "el divorcio generado entre lo que es la revelación y lo que ella exige fundamentalmente (o amor) y aquello de lo que se ocupa fundamentalmente la teología (explicación, profundización de verdades)", op. cit., p. 75.

46. C. Boff, Teoria do método teológico, op. cit., p. 117.

47. C. Boff, Teoria do método teológico, op. cit.; y Teoria e prática, op. cit., p. 147.

48. Ibidem y en "Teologia e prática", REB 36/144, 1976, 789-810, aquí 796.

49. C. Boff, Teoria do método teológico, op. cit., p. 391. Y también pp. 112, 121, 168. "Las leyes del pensamiento, bien como las del lenguaje, son diferentes a las de la realidad. El orden del ser no es el orden del conocer" (ibid., pp. 216, 341).

50. Cfr. L. Wittgenstein, Philosophische Untersuchungen, op. cit., § 23. 
Y ella se desenvuelve y se configura, precisamente, como intelección del reinado de Dios en la historia. No es verdad, como piensa Clodovis Boff, que "una práctica teológica como tal sólo es 'culpable' de los criterios de su gramática, esto es, del conjunto de reglas que organizan su discurso" "51. Ella tiene que responder también y en última instancia por la capacidad de aprehender y formular de modo más o menos adecuado la realidad que busca inteligir, esto es, el reinado de Dios. Él es no solo punto de partida de la teología, sino su principio, su fundamento y su criterio permanente. Es ahí donde, en última instancia, se juega la veracidad o falsedad de una teología, en cuanto actividad intelectiva: "en la marcha intelectiva, las cosas comienzan dando que pensar y terminan dando [o quitando] razón" 52 .

Tomando como criterio la praxis de Jesús de Nazaret, según las Escrituras, compete a la teología, por lo tanto, discernir e identificar en los procesos históricos los signos de la realización del reinado de Dios en este mundo y formularlos del modo más adecuado y consecuente posible. Y aquí entran en juego todas las mediaciones prácticas y teóricas necesarias, tanto para el acceso a la praxis de Jesús de Nazaret como para el discernimiento del dinamismo histórico desencadenado por ella (1 Cor 4,20; 1 Jn 2,6), o acorde o identificado con ella (Lc 10,25-37; Mt 25,31-46). Pero esa es ya otra cuestión.

Aquí nos interesa simplemente insistir en el carácter y en el potencial epistemológico del reinado de Dios como asunto de la teología cristiana, en la medida en que al determinar y formular con precisión ese "ámbito de realidad", se determina también, en buena medida, su acceso intelectivo y el propio proceso de intelección. Y tanto en lo que dice respecto a su punto de partida como en lo que dice respecto a su desarrollo y a las mediaciones necesarias para tal desarrollo.

\section{A modo de conclusión}

La determinación y la formulación adecuada del asunto de la teología cristiana son de fundamental importancia, tanto para su desarrollo sistemático (desarrollo de varios temas, problemas, aspectos, etc., en su especificidad y en su unidad radical) como para explicitar y potenciar su modo de conocimiento (punto de partida, mediaciones prácticas y teóricas, y configuración). Ellas dicen respecto a la identidad cristiana de la teología (trata todo a partir del y en vista del reinado de Dios) y, consecuentemente, al propio método teológico (reinado de Dios como determinante del proceso de conocimiento teológico). De ahí su carácter y su importancia sistemática-epistemológica.

51. C. Boff, Teoria e prática, op. cit., p. 60.

52. X. Zubiri, Inteligencia y razón, p. 71 (Madrid: Alianza, 2001). 
Ciertamente, es necesario determinar con mayor precisión lo que fue el reinado de Dios en la vida de Jesús de Nazaret y cómo se viene realizando a lo largo de la historia - "dos tareas estrictamente teológicas". Y cuanto más se avance en estas tareas, tanto más se avanzará en el desarrollo de los contenidos teológicos y en la profundización del modo de conocimiento teológico. Pero todo eso ya es parte del proceso de intelección de ese "ámbito de realidad" que es el reinado de Dios, y en cuanto tal, está, en buena medida, condicionado y determinado por él, una vez que el reinado de Dios es EL asunto de la teología cristiana. 